\title{
0 software GeoGebra e a Engenharia Didática no estudo de áreas e perímetros de figuras planas
}

Prof. Dr. José Carlos Pinto Leivas

Msc. Juliana Aparecida Gobbi

\section{Resumo}

Este artigo é recorte de uma pesquisa de Mestrado Profissionalizante em Ensino de Matemática, com alunos de 6a série do Ensino Fundamental. Foi realizada pela primeira autora, orientada pelo segundo autor e trata do cálculo de perímetro e área de figuras planas. Surgiu devido às inquietações da pesquisadora sobre sua prática pedagógica, bem como pelo fascínio dos alunos pelas tecnologias. Teve como objetivo investigar como esses alunos realizam a construção do conhecimento de um assunto com a utilização do GeoGebra. A metodologia seguiu as etapas da Engenharia Didática e a pesquisa foi realizada durante $o$ ano de 2011, num período de 30 dias, num total de 12 horas aula de 50 minutos. Concluímos que a aplicação da sequência didática ajudou na aprendizagem dos alunos, pelas contribuições obtidas pelo uso do software, pois tornou as aulas dinâmicas e possibilitou o entendimento dos alunos sobre 0 cálculo de perímetros e áreas, completando uma lacuna existente do ensino da geometria.

Palavras-chave: livro didático, engenharia didática, GeoGebra, perímetros e áreas.

Abstract

The software GeoGebra and Didactic Engineering in study of areas and perimeters of the plane figures

This article is clipping from a research of Professional Master in Teaching of Mathematics, conducted with students from 6th grade of Elementary School; conducted by the first author under the guidance of the second author in the study of the calculate of the perimeter and area. It emerged due to concerns of the author him practice and the allure that students have for the technology. It aimed to investigate how students perform for the construction of knowledge using the software GeoGebra. The methodology followed the steps of the Didactic Engineering and the survey was conducted during the year 2011, for a period of 30 days totaling 12 lessons of 50 minutes. We can conclude that the application of didactic sequence helped in student learning for the use of software because the dynamic's classes allowed the student understanding about perimeters and areas.

Keywords: textbook, didactic engineering, GeoGebra, perimeters and areas. 


\section{Introdução}

Apresentamos neste item algumas considerações teóricas, à luz da literatura, sobre tecnologias aplicadas ao ensino, sobre geometria e também alguns pressupostos da metodologia da engenharia didática.

\subsection{Tecnologias}

As tecnologias, muitas vezes, têm assustado e desacomodado professores. Se, por um lado, faltam metodologias apropriadas para utilizá-las, por outro lado, falta aceitar mudanças das velhas formas de propor problemas, os quais não podem ser do mesmo tipo daqueles que eram propostos sem o uso da tecnologia computacional. Acreditamos que a escola tem o papel fundamental de utilizar os recursos tecnológicos com os alunos, pois o mundo está rodeado deles. Deve-se ter cuidado em assumir que o uso de tais recursos não resolve os problemas existentes, porque esses não garantem, sozinhos, transformações na prática pedagógica, nem alteram a educação escolar. Sancho e Hernández (2006, p. 18) afirmam que "as tecnologias da informação e comunicação estão aí e ficarão por muito tempo, estão transformando o mundo e deve-se considerá-las no terreno da educação".

Compactuamos com Pais $(2008$, p. 173), quando se refere ao uso de tecnologias para o ensino, ao afirmar que essa "seja uma tendência irreversível e necessária para a expansão da educação escolar". Em relação ao emprego das tecnologias pelos professores, o autor afirma (p.15): “[...], deverão se empenhar diretamente no processo da própria qualificação, para acompanhar o ritmo das mudanças motivadas pelo uso das novas tecnologias [...]", e isso faz com que aprimorem suas aulas, por meio de atividades dinâmicas, ampliando situações de aprendizagem, as quais aproximam os alunos de abordagens mais práticas, experimentais, ligando-as a situações reais e do seu dia-a-dia.

A respeito das Tecnologias de Informação e Comunicação - TIC, encontramos nos Parâmetros Curriculares Nacionais - PCN, a seguinte informação: "em suas diferentes formas e usos, constituem um dos principais agentes de transformação da sociedade, pelas modificações que exercem nos meios de produção e por suas consequências no cotidiano das pessoas" (BRASIL, 1998, p.43). Por isso, acreditamos que elas devam estar inseridas na prática escolar.

\subsection{Geometria}

Os PCN enfatizam a Geometria como parte fundamental na construção do conhecimento do aluno. Por isso, ela não pode ser abandonada nas aulas, as quais devem ser interessantes e motivadoras. O professor, negando a oportunidade do aluno em aprendê-la, acaba deixando de 
envolvê-lo no que há de mais valioso no processo de ensino e de aprendizagem, que é a busca pela construção de conceitos. O conceito pode ser construído por meio da manipulação do objeto geométrico nas suas diferenças e representações. A compreensão do mesmo remete à compreensão de outros conceitos. No transcorrer do processo de aprendizagem, o aluno parte de um determinado nível de compreensão preliminar para esclarecer noções e conceitos, sendo polidos e refinados, necessitando estar em permanente aprendizagem. Ainda sobre os PCN, esses "conceitos geométricos constituem parte importante do currículo de Matemática no Ensino Fundamental - E.F., porque, por meio deles, o aluno desenvolve um tipo especial de pensamento, o qual Ihe permite compreender, descrever e representar, de forma organizada, o mundo em que vive" (BRASIL, 1998, p.51).

\subsection{Engenharia didática}

Uma das metodologias atuais em Educação Matemática, oriunda da chamada Didática Francesa, é a Engenharia Didática - ED e sua criadora é Michele Artigue. Essa metodologia pode ser entendida tanto como uma metodologia de pesquisa específica, quanto como uma sequência de aulas ou atividades concebidas e organizadas de forma coerente. Para Machado (1999), ela se caracteriza como um esquema experimental baseado nas "realizações didáticas" em sala de aula, isto é, sobre a concepção, a realização, a observação e a análise de sequências de ensino. É possível distingui-la em dois níveis: o da microengenharia, que tem como objetivo o estudo de um determinado assunto e leva em conta a complexidade dos fenômenos na sala de aula e o da macroengenharia, que compõe a complexidade das pesquisas de microengenharia com os fenômenos ligados à duração nas relações entre ensino e aprendizagem.

A ED é formada pelas quatro fases apresentadas a seguir.

1. Análises preliminares, nas quais se observam a análise epistemológica dos conteúdos, a análise do ensino atual, a análise das dificuldades e obstáculos e a do campo onde vai situar-se a realização didática.

2. Concepção e análise a priori, em que o pesquisador delimita certo número de variáveis sobre os quais o ensino pode atuar.

3. Experimentação, que é a fase da realização da engenharia, a qual se inicia no momento em que se dá o contato pesquisador/professor/observador e supõe a explicitação dos objetivos e condições de realização da pesquisa, seguindo com a aplicação dos instrumentos de pesquisa e o registro das observações feitas.

4. Análise a posteriori e a avaliação, que se apoia sobre todos os dados colhidos durante a experimentação. 
O confronto entre as análises a priori e a posteriori irá validar ou não a pesquisa. Em particular, verifica-se se houve ou não crescimento na formação do aluno e se os objetivos propostos foram alcançados.

A nossa opção pela ED, como metodologia empregada, ocorreu pelo fato de que ela é atual e consideramos que planejar cuidadosamente aulas em que os alunos sejam agentes da construção do seu conhecimento faz parte de nossas convicções como professores com certa experiência no magistério.

\section{Justificativa para a pesquisa}

O presente artigo refere-se a um fragmento de uma pesquisa realizada no Mestrado Profissionalizante em Ensino de Matemática em que investigamos, por meio de uma sequência didática, quais as contribuições que o software GeoGebra pode proporcionar na aprendizagem de áreas e perímetros de algumas figuras geométricas planas, por alunos de um sétimo ano (6a série) do EF do qual a primeira autora foi a docente.

Justificamos a escolha por querermos despertar nos alunos interesse pelo aprendizado e, para tal, acreditamos poder fazer uso do grande interesse que eles possuem pelas tecnologias. Além disso, unindo o fascínio que os alunos têm pelas TIC como o nosso pela Geometria, acreditamos poder aperfeiçoar a função docente desejada para um mestrado profissionalizante em seus princípios, no que diz respeito ao ensino além de melhorar a aprendizagem matemática dos alunos. Assim, ao aprimorar a função como docente, que procura o mestrado, faz com que os alunos sejam participantes ativos do próprio saber. Isso corrobora o que Kenski (2007) afirma sobre as TIC: "quando bem utilizadas, provocam a alteração dos comportamentos de professores e alunos, levando-os ao melhor conhecimento e maior aprofundamento do conteúdo estudado" (p.45).

Além disso, a utilização de um software educacional permite uma maior interatividade entre os alunos e entre alunos-professor, resultando em troca de informações qualitativas. A mesma autora afirma que "softwares diferenciados transformam a realidade da aula tradicional, dinamizam o espaço de ensino-aprendizagem, onde, anteriormente, predominava a lousa, o giz, o livro e a voz do professor" (p.46).

Na pesquisa realizada, utilizamos o software GeoGebra, o qual busca integrar a Geometria e a Álgebra, auxiliando no processo de pensar, refletir e criar soluções durante a execução das atividades. Foi desenvolvido para ser utilizado de forma livre em um ambiente de sala de aula e para fazer o download do programa, disponível em http://www.geogebra.org/cms. Para acessá-lo deve-se ter a linguagem Java. 
A fim de justificar o tema da pesquisa, realizamos uma análise num dos recursos mais utilizados pelos professores nas salas de aulas, que é o livro didático. Fizemos um levantamento de livros avaliados e indicados pelo Plano Nacional dos Livros Didáticos - PNLD da área de Matemática referentes ao $1^{\circ}$ ano até a 6. 9 /70. ano do ensino básico, identificando de que maneira eles abordam Geometria. A análise comprovou que poucas formas alternativas ao ensino tradicional são oferecidas, entretanto, o conteúdo de áreas e perímetros é relacionado nas diversas séries/anos.

Partimos, então, para a definição do seguinte problema de pesquisa: de que maneira o uso do GeoGebra pode contribuir para o estudo de perímetros e áreas de figuras geométrica planas, a partir da Engenharia Didática?

\section{Caminhos metodológicos}

A pesquisa teve como metodologia a ED a qual se baseia no conceito de sequência didática. Segundo Pais (2002, p. 102), uma sequência didática "é formada por um determinado número de aulas planejadas e analisadas previamente com a finalidade de observar situações de aprendizagem, envolvendo os conceitos previstos na pesquisa didática". Tendo caráter específico de pesquisa, as aulas preparadas para uma sequência didática não são aulas de rotina. Por isso, é importante, durante a sua preparação e aplicação, observar todas as informações possíveis, que possam contribuir para o aprendizado dos alunos.

\section{Primeira fase: análise preliminar}

Para a escolha do assunto perímetro e área de figuras geométricas planas, foi importante fazermos uma análise dos livros didáticos, verificando o que eles abordam de Geometria, a fim de fazer uma avaliação diagnóstica, para termos um mapeamento do conhecimento prévio dos alunos sobre o conteúdo escolhido.

\section{Segunda fase: concepção e análise a priori}

Feita a análise dos livros didáticos, elaboramos uma avaliação diagnóstica por meio da aplicação de atividades retiradas dos livros analisados e aplicamos a 40 alunos de duas turmas, nas quais a investigadora foi à professora titular. Após a análise dos resultados da avaliação diagnóstica, elaboramos uma sequência didática envolvendo o conteúdo perímetro e áreas com a utilização do software GeoGebra.

A avaliação diagnóstica detectou que os alunos ainda não tinham conhecimentos do assunto dos dois conteúdos por constar dos programas desse nível em que eles se encontram. Por outro lado, os alunos ainda não tinham utilizado o GeoGebra e nem outro qualquer software tanto para o ensino de Matemática quanto para outras disciplinas. Em face do último 
desconhecimento, as figuras foram todas previamente adaptadas e elaboradas pela pesquisadora e disponibilizadas aos alunos nos computadores que utilizariam para a investigação.

Os ajustes na sequência elaborada foram sendo feitos na medida em que se desenrolavam as aulas no Laboratório de Informática e com o envolvimento dos estudantes, o que vai ao encontro do que Douady (1999, apud MACHADO, 1999, p.198) afirma: "o projeto evolui sob as reações dos alunos em função das escolhas e decisões do professor".

\section{Terceira fase: experimentação}

Elaborada a sequência de atividades, partimos para a experimentação nas duas turmas, concomitantemente, a fim de que pudéssemos, posteriormente, estabelecer comparativos entre o que ocorreria com cada uma delas. Para Almouloud (2001), a fase da experimentação é a mais importante, pois ela permite "ao aluno agir, se expressar, refletir e evoluir por iniciativa própria, adquirindo, assim, novos conhecimentos" (p. 174). Além disso, o aluno desenvolve suas habilidades, utiliza diferentes representações matemáticas como, por exemplo, o desenvolvimento do raciocínio dedutivo. O professor, como mediador e orientador, intervém de maneira participativa no processo de aprendizagem do aluno. Com essa concepção é que nos concentramos durante a experimentação da sequência didática no período investigativo.

\section{Aplicação das sessões}

As sessões em que a sequência didática foi aplicada se realizaram no laboratório de informática da escola, durante os períodos regulares de aula de Matemática, com duas turmas de sexta série/sétimo ano em que a investigadora é a docente. Cada aluno abriu uma pasta num mesmo computador que utilizou durante todas as sessões para a realização de suas atividades, colocando nela todas as tarefas realizadas no decorrer das aulas. A análise dos registros feitos nessas pastas proporcionou os resultados de nossa pesquisa. A docente da turma com a ajuda da professora do laboratório de informática colocou uma pasta em cada computador do laboratório de informática com todas as atividades elaboradas. Os alunos abriam essa pasta para resolver cada atividade, após a resolução cada aluno colocou as tarefas em suas pastas.

Por considerarmos grande o número de alunos participantes, a análise das atividades foi feita de maneira intercalada, permitindo, assim, analisar as respostas de todos os alunos participantes da pesquisa, muito embora nem todas, de todos. Usamos para análise das respostas dos alunos o critério a seguir.

1. Os alunos da turma 61 foram nomeados com as letras de $A$ até $T$.

2. As atividades de ordem ímpar analisadas foram as dos alunos $A, C, E, G, I, K, M, O, Q$ e $S$.

3. As atividades de ordem par analisadas foram as dos alunos $B, D, F, H, J, L, N, P, R, T$.

4. Os alunos da turma 62 foram nomeados com as mesmas letras anteriores, porém com apóstrofe de $A^{\prime}$ até $T^{\prime}$.

R. B. E. C. T., vol 7, núm. 1, jan-abr.2014 ISSN - 1982-873X 
5. As atividades de ordem ímpar analisadas foram as resoluções dos alunos $A^{\prime}, C^{\prime}, E^{\prime}, G^{\prime}, I^{\prime}$, $K^{\prime}, M^{\prime}, O^{\prime}, Q^{\prime}$ e $S^{\prime}$.

6. As de ordem par foram as dos alunos $B^{\prime}, D^{\prime}, F^{\prime}, H^{\prime}, J^{\prime}, L^{\prime}, N^{\prime}, P^{\prime}, R^{\prime}$ e $T^{\prime}$ e assim sucessivamente.

Dessa maneira, tivemos uma abrangência das respostas apresentadas por todos os alunos ao término da aplicação das sessões e a comparação do que esperávamos na análise a priori com os resultados obtidos.

A sequência de atividades elaboradas para a investigação foi dividida em quatro sessões. Cada uma delas teve atividades cuidadosamente elaboradas, de modo a alcançar os objetivos da sessão, conectadas àquelas propostas na avaliação diagnóstica, sempre utilizando o GeoGebra. A primeira sessão- cálculo de área e perímetro - teve como objetivo verificar se os alunos conseguiam completar as figuras dadas por meio de quadrados e metades de quadrados (triângulos) para chegar ao cálculo de suas áreas e seus perímetros.

A segunda sessão- equivalência de áreas - tinha por objetivo verificar se os alunos conseguiam perceber a equivalência de áreas das figuras dadas e obter os valores correspondentes. A terceira - áreas e perímetros de retângulos e quadrados - consistia em verificar se os alunos conseguiam obter uma relação e formalização para o cálculo de áreas e perímetros.

Por fim, a quarta sessão - áreas e perímetros de quadriláteros - teve como objetivo verificar se os alunos conseguiam perceber uma relação entre áreas de duas figuras geométricas planas, obtendo, assim, a equivalência de áreas.

Escolhemos, para apresentar neste artigo, a sessão 3, a análise feita pelos estudantes e a relação entre análise a priori e a posteriori. Tal escolha não teve um motivo específico por ser mais ou menos importante e, sim, pela limitação de espaço para um artigo e, também, porque outras sessões foram indicadas para artigos, até mesmo pelo volume constante na própria dissertação. 


\section{Detalhando o recorte ${ }^{1}$}

A sessão foi aplicada em dois períodos de aula de Matemática, de cinquenta minutos cada um e a primeira atividade proposta foi a seguinte:

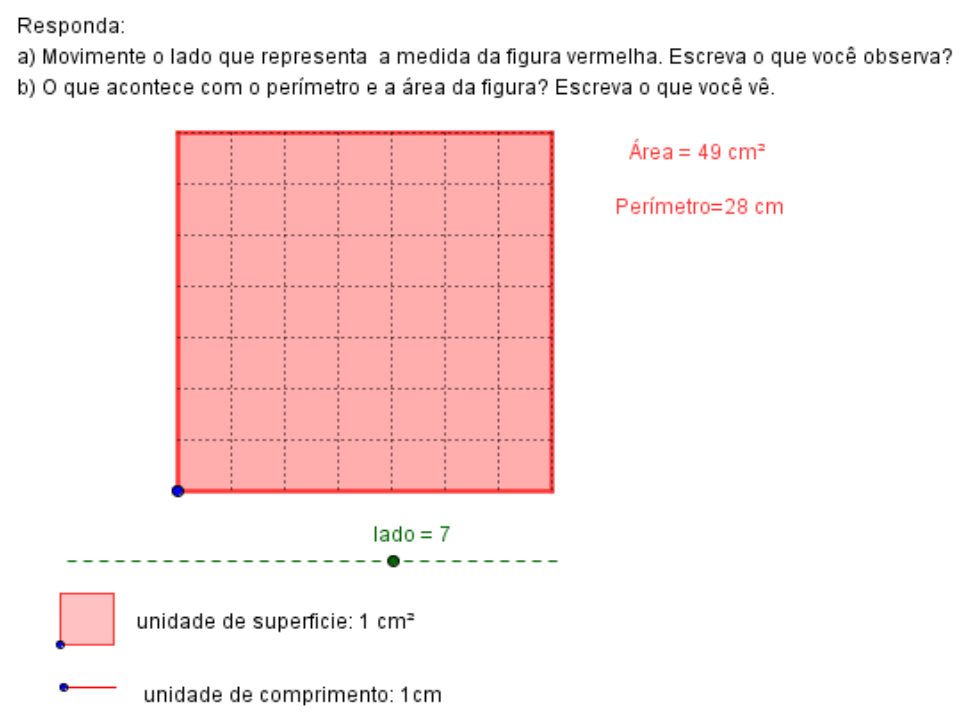

Figura 1 - Primeira atividade da sessão 3.

Esperávamos que os alunos, ao fazerem variar o lado do quadrado, encontrassem uma nova figura de maior ou menor lado, percebendo que existe uma relação entre a área da figura e o seu perímetro. Assim, deveriam obter a generalização para obtenção da área, que é igual à medida do lado ao quadrado ou medida do lado vezes a medida do outro lado. . Além disso, o perímetro é igual a quatro vezes a medida do lado do quadrado. Propomos, então, as perguntas, às quais os alunos deveriam responder em uma caixa de texto aberta na própria janela de visualização em que estava a atividade proposta, como enunciada na figura 1, anterior.

A análise das respostas fornecidas pelos estudantes indica que 12 dos 20 alunos conseguiram perceber que o deslocamento do ponto para a direita aumentava a área da figura e, para a esquerda, diminuía. Entretanto, não foi percebida qual era a relação entre a área e o perímetro. Os dados mostram que um aluno percebeu que a área da figura é igual à medida do lado ao quadrado. Ele utilizou a raiz quadrada para interpretá-la, pois visualizou o cálculo da área e relacionou o resultado com o valor com que representou o lado. Os demais alunos perceberam que existe uma relação entre o perímetro e a área, mas não a concluíram.

A análise a posteriori da atividade mostrou que os estudantes sentiram dificuldade em relacionar área e perímetro e não chegaram a uma generalização para a atividade. Para Teles e Bellemain (2011), as fórmulas têm um papel fundamental no processo do conhecimento do aluno,

\footnotetext{
${ }^{1}$ Adaptada de <http://geometriadinamica.es/Tabla/Geometria>
} 
mas elas podem ser vistas com múltiplos olhares, dependendo dos usos e dos sentidos que thes atribuímos. Por isso, acreditamos que eles não conseguiram perceber o sentido dessa relação.

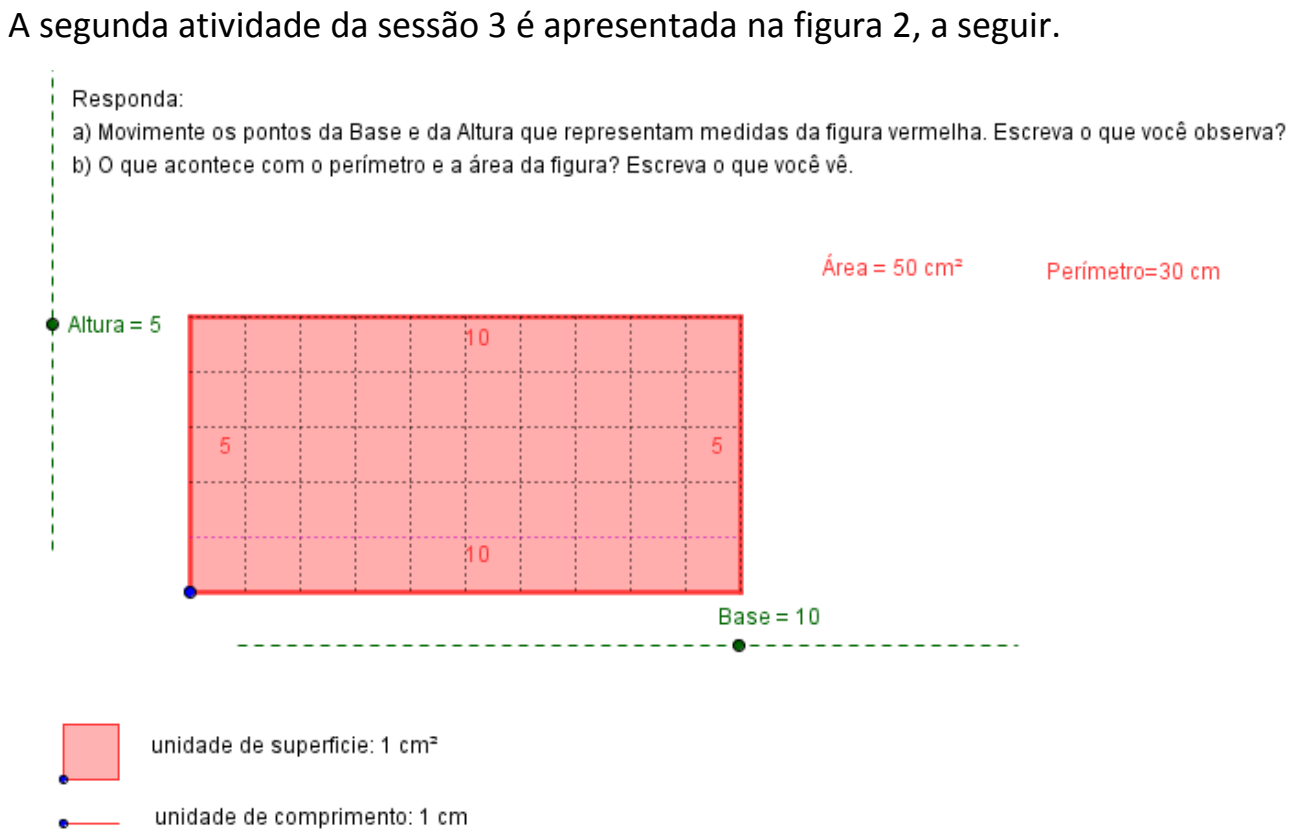

Figura 2 - Atividade 2 da sessão 3.

Esperávamos, durante a atividade que, ao movimentarem a base e a altura do retângulo, modificando-os, percebessem que existe uma relação entre a área da figura e o seu perímetro. Assim, obteriam a generalização da área que é obtida pelo produto da medida da base pela medida da altura. Também, que o perímetro é igual à soma das medidas dos lados. Além disso, pretendíamos que visualizassem que, quando a base e a altura alcançassem a mesma medida, encontrariam um quadrado.

Constatamos a dificuldade dos alunos em interpretar o que fora solicitado, muito embora a metade dos investigados tenha concluído haver modificação no valor, tanto da área quanto do perímetro. Ainda não foi possível avançar em relação ao item posterior, uma vez que dez alunos continuavam afirmando terem aumentado ou diminuído, tanto a área quanto o perímetro, com a variação da medida dos comprimentos dos lados. Por outro lado, o fato de apenas um aluno não ter respondido, mostra o envolvimento ou o comprometimento deles com as atividades e isso já dá indícios da contribuição que o software está proporcionando para o ensino.

A análise a posteriori dessa atividade evidenciou que o objetivo proposto não foi alcançado, uma vez que os alunos não conseguiram observar que o valor aumentado na medida de um dos lados tinha correspondência com um acréscimo em dobro na medida do perímetro. De forma similar, não foi detectado, naquele momento, que o valor acrescido na variação da medida de um lado tem por correspondência um acréscimo na área que corresponde ao valor do produto desse acréscimo pela medida do outro lado. 
A figura 3, a seguir, ilustra a terceira atividade proposta para a sessão.

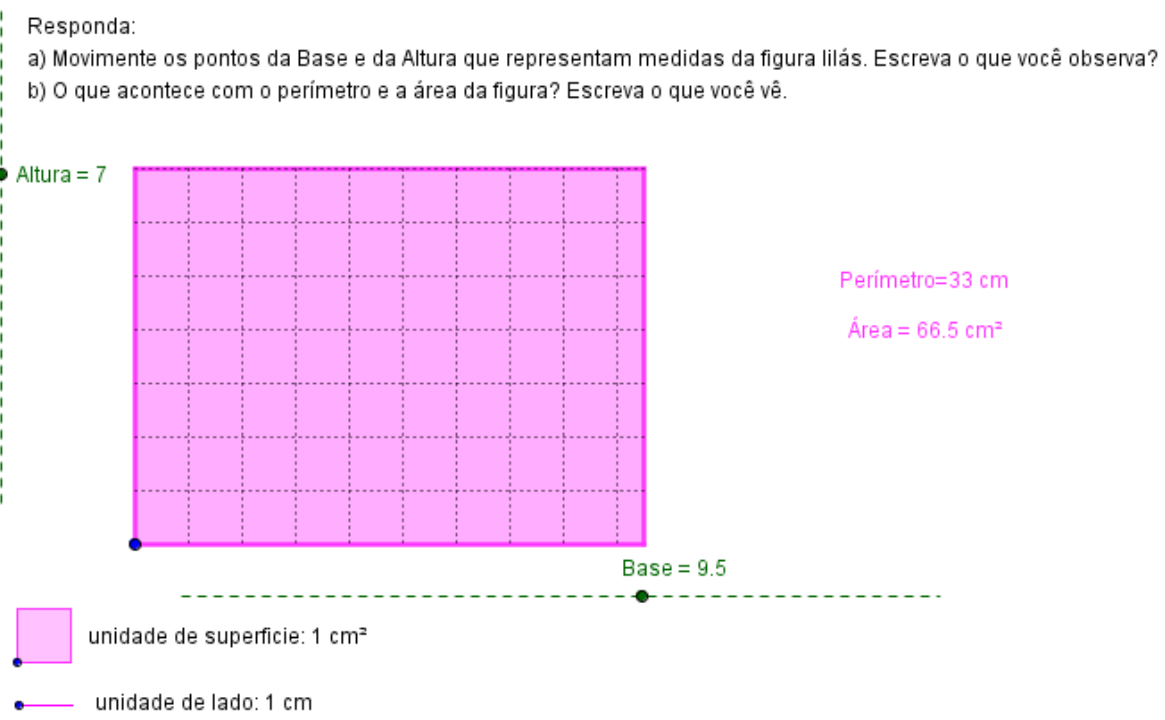

Figura 3 - Atividade 3 da sessão 3.

Havia a expectativa, nessa atividade, de que os alunos percebessem existir uma relação entre a medida da área e a do perímetro da figura. Assim, obteriam a generalização do cálculo da área, que é o produto da medida da base pela medida da altura. Esperávamos, também, que concluíssem que o perímetro é obtido multiplicando duas vezes a medida da base e somando com duas vezes a medida da altura. Também pretendíamos que visualizassem que, quando a base e a altura tivessem o mesmo valor, teriam, em vez de multiplicação dos dois valores, o seu quadrado. Essa atividade diferia da anterior pelo fato de terem sido empregados números decimais.

De forma similar, à análise a posteriori feita para a atividade anterior não ocorreu, o que era esperado dos alunos na análise a priori, uma vez que nenhum deles conseguiu relacionar a variação das medidas dos lados com os valores obtidos para a área e o período. O que foi possível observar é que somente o aluno $\mathrm{K}$ ' destacou que a “diferença em relação aos resultados anteriores está no fato de obter resultados com vírgula". 
A atividade 4 da sessão 3 é apresentada na figura 4, a seguir.

Responda:

a) Ao movimentar o ponto que indica o lado da figura, escreva o que você vê.

b) 0 que acontece com o perímetro e a área da figura? Escreva o que você vê.

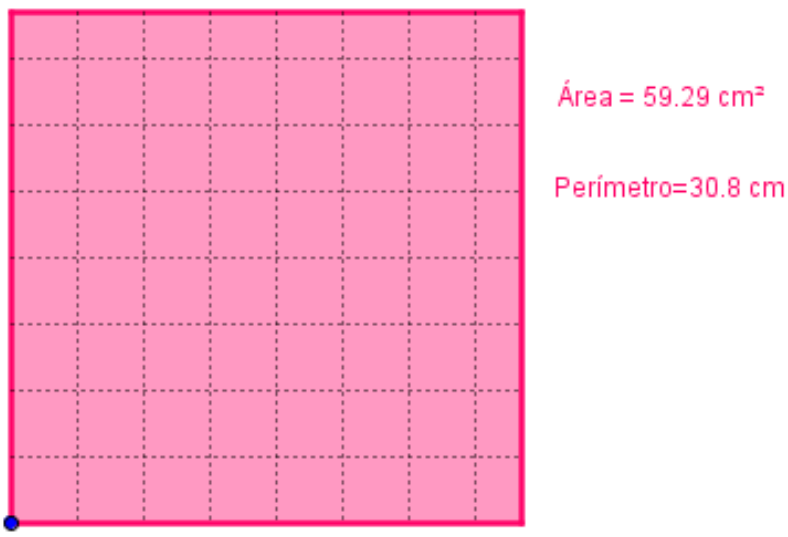

Iado $=7.7$

unidade de superficie: $1 \mathrm{~cm}^{2}$

- unidade de lado: $1 \mathrm{~cm}$

Figura 4 -Atividade 4 da sessão 3.

Esperávamos que os alunos, ao movimentarem o lado do quadrado, obtivessem quadrados com lados diferentes e, modificando-o, percebessem existir uma relação entre as duas grandezas da figura, a área e o perímetro, com as medidas dos lados. Assim, obteriam a generalização.

Os seis alunos que responderam que o quadrado aumenta ou diminui de tamanho perceberam que continuam tendo um quadrado, o que já é importante, pois conseguem visualizar que o objeto não se deforma. Nesse sentido, os aspectos visuais obtidos pelo GeoGebra foram facilitadores para esses indivíduos, muito embora ainda não tivessem percebido que as modificações ocorram de acordo com a variação da medida do lado elevada ao quadrado. É provável que não tivessem ainda em mente os aspectos algébricos oriundos da potenciação.

Com relação ao segundo questionamento proposto, os alunos não perceberam nenhuma relação entre o perímetro, a área e as medidas dos lados da figura dada. Das vinte respostas aqui categorizadas, constatamos que apenas seis alunos responderam "aumentam e diminuem na vertical e na horizontal". Apenas um aluno observou que, ao movimentar para a esquerda, a área diminui e o perímetro aumenta e, quando para a direita, ocorre o inverso.

Da análise a posteriori, feita após cada uma das atividades que constituem a atividade 4, pudemos concluir que os alunos perceberam o que acontecia na atividade, movimentando o lado da figura, escrevendo, assim, que a figura aumenta e diminui de tamanho. Isso resulta no cálculo de área e perímetro. Entretanto, não visualizaram uma relação entre as duas grandezas com relação à medida de seus lados como eram esperado na análise a priori da atividade. 
A atividade 5 da sessão 3 é apresentada na figura 5, a seguir.

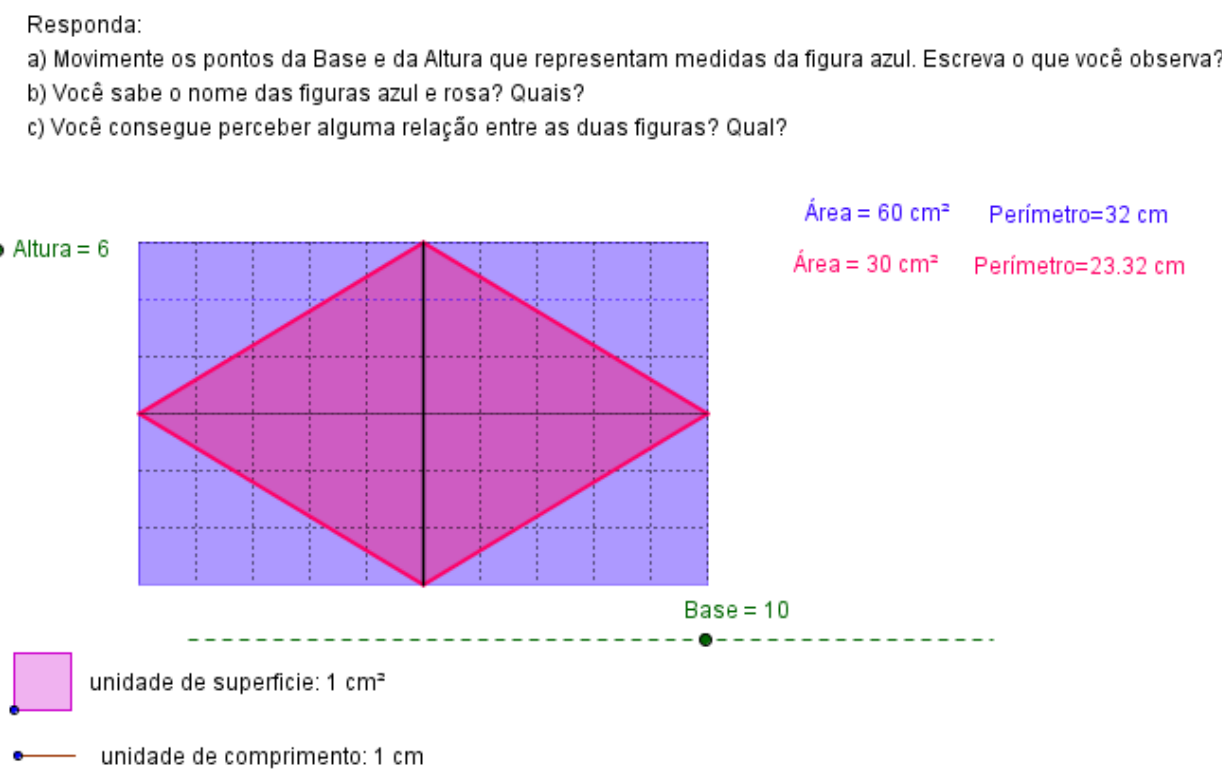

Figura 5 -Atividade 5 da sessão 3.

$\mathrm{Na}$ análise a priori desta atividade, era esperado que os alunos, ao movimentarem os pontos que geravam, por assim dizer, a base e a altura formariam um retângulo. Este aparece como um losango sobreposto, o que mascara a visualização do retângulo. Durante o uso do GeoGebra e das movimentações, os alunos puderam perceber claramente a existência de duas figuras, o que não acontece quando temos a representação estática em papel, como na figura 5. Devemos levar em conta que a figura rosa, em geral, é denominada de losango. Assim, com o dinamismo do GeoGebra, esperávamos que os alunos pudessem partir desse losango e chegar à obtenção de retângulo e quadrado. Dessa forma, estariam relacionando as áreas das figuras, em que a da azul corresponderia ao dobro da rosa.

Em nossa percepção, no transcorrer da atividade, houve muita dificuldade em visualizar a transformação das figuras. Além disso, não conseguiram, também, verificar que o losango poderia se transformar no retângulo, na medida em que suas diagonais maior e menor se aproximassem em termos de medidas, para, finalmente, se tornarem lados congruentes do retângulo, situação em que o retângulo e o losango se transformariam no quadrado.

Durante as aulas, a professora procurou ir apresentando, em suas falas, os nomes corretos das figuras. Isso pode ter ocasionado nos alunos a vontade de denominá-las em suas escritas, para responderem ao segundo item dessa atividade. Além disso, as propriedades que classificariam as figuras em retângulos, losangos e quadrados não estavam em jogo. Chama atenção o fato de cinco alunos terem caracterizado as duas figuras iniciais como quadrado, dois em cada turma terem afirmado que a rosa é um triângulo e a figura azul é um quadrado e um responder que a figura rosa é um quadrado. Um dos alunos percebeu que a figura rosa é formada 
por vários triângulos, o que não deixa de estar correto. Apenas um aluno notou que o nome das figuras dependia da medida da altura e da base para classificá-las.

Nas respostas ao terceiro item, é possível intuir que o fato das transformações obtidas na movimentação feita no GeoGebra levou o aluno I a concluir que as duas são "meio triangulares" o que parece ser importante, pois ele podia estar visualizando os quatro triângulos rosa e os quatro azuis se transformando continuamente, sem perderem a característica de triângulos. $O$ fato percebido por cinco alunos de que não há alteração na altura e na base (medidas) com a movimentação proporcionada pelo software fez com que classificassem a figura como quadrado. O visual obtido na tela do computador pela variação do losango pode ser o que levou dois alunos a responderem "Sim, elas são as mesmas figuras, mas a área e o perímetro são diferentes".

Com relação à análise a posteriori da atividade 5 , podemos considerar como positivo os resultados obtidos e o objetivo sendo alcançado, uma vez que o GeoGebra permitiu a movimentação das figuras, sua transformação, a nomenclatura e algumas propriedades foram sendo adquiridas. Por exemplo, quando o aluno K afirma que "sim, elas são as mesmas figuras, mas a área e o perímetro são diferentes", ele está utilizando a movimentação dos pontos e a sobreposição (figura 5) para perceber que a altura e o comprimento variam nas duas, azul e rosa. Elas representam as diagonais do losango, as quais irão corresponder aos lados do retângulo, sendo uma delas a base e a outra, a altura.

No que segue, apresentamos a atividade 6 (figura 6).

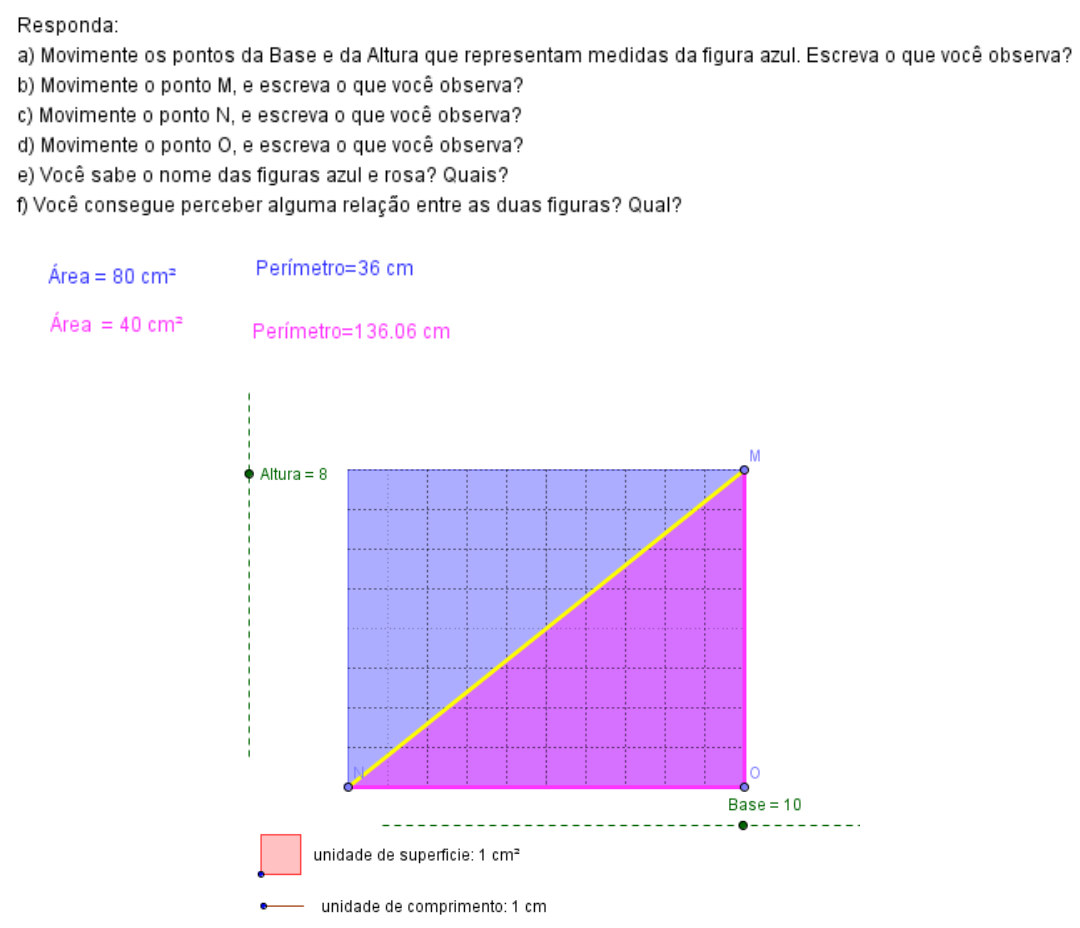

Figura 6 - Atividade 6 da sessão 3. 
$\mathrm{Na}$ análise a priori, esperávamos que os alunos, ao movimentarem os pontos que representam a base e a altura, observassem a mudança no tamanho da figura, bem como a mudança no seu perímetro e na sua área. Deveriam perceber, também, existir uma relação entre as figuras azul e rosa. Nesse caso, a área da azul é igual ao dobro da rosa, uma vez que a última está sobreposta à primeira e, ao movimentar a base e a altura, a figura rosa faz um rastreamento sobre a azul, deixando-a oculta, mostrando a importância da utilização do GeoGebra em relação à representação estática. Além disso, dependendo da posição em que o ponto é colocado, muda somente uma das grandezas, o perímetro ou área. No geral, mudam os dois ao mesmo tempo. Esperávamos que houvesse a identificação das relações encontradas nas figuras e os respectivos nomes.

Os dados coletados mostraram que seis alunos, dos treze presentes, afirmaram que, tanto a medida da altura quanto a da base aumentava e diminuía, enquanto que cinco deles afirmaram haver mudança na área e no perímetro. A aluna $\mathrm{H}$ escreveu que "quando movimentamos o lado que representa a base da figura para a esquerda, a área e o perímetro diminuem". Assim, podemos afirmar que os alunos perceberam que a variação na medida da base e da altura mudava o perímetro e a área das figuras.

Com relação às respostas ao item $b$ dessa atividade, entendemos que não atenderam ao esperado na análise a priori, porque não conseguiram perceber a relação entre as áreas e os perímetros das duas figuras. A resposta do aluno $\mathrm{H}$, afirmando que, "se mexer o ponto $\mathrm{M}$ para a esquerda, o perímetro diminui", é algo sem nexo, talvez não sendo isso o que queria expressar. É possível que estivesse pensando na redução da área ou do perímetro da figura azul.

Em relação ao respondido no terceiro item, até certo ponto, pudemos notar a dificuldade de expressar, em língua materna, as observações, como ingenuamente responderam três alunos: "Ele sobe e desce e as figuras rosa e azul mudam"; "O ponto N muda de lugar". Não houve busca de relações matemáticas envolvidas, e sim preocupação com o dinamismo que o software oferece para transformação das figuras.

No que diz respeito ao quarto item, podemos perceber que houve, a partir desse, uma melhoria em relação às relações matemáticas, uma vez que dois alunos expressaram: "A área da figura rosa diminui e o perímetro fica do mesmo jeito", o que nos parece já ser um avanço obtido na resolução da sequência didática proposta.

Preocupou-nos o fato de que sete dos treze alunos não responderam ao item e, quanto ao que fora solicitado, apenas um aluno afirmou ser (em) triângulo(s) e três afirmaram ser a figura azul um quadrado. Como cada aluno percebeu uma relação diferente nas suas observações quanto ao item $\mathrm{f}$, destacamos a resposta do aluno $\mathrm{P}$ : “A área da figura azul é o dobro da área da figura rosa e o perímetro é menor que o da figura rosa". Isso nos demonstrou um crescimento na aquisição das relações pretendidas, sendo possível, também, deduzir que o GeoGebra favoreceu 
essa aquisição, uma vez que os alunos perceberam a variação e/ou conservação de formas geométricas, como descrita por K’: "sim, elas se movem juntas; sim, são triângulos iguais".

$\mathrm{Na}$ análise a posteriori sobre a última atividade descrita e analisada, podemos inferir que, muito embora não tenha sido alcançado o objetivo principal da sequência elaborada nessa atividade, pois os alunos não perceberam a relação de que a área de uma era o dobro da outra, outras conquistas foram obtidas, como a nomenclatura das figuras e a conservação de formas geométricas.

Proporcionamos aos alunos outras atividades para fazerem, relacionando a área e o perímetro de figuras geométricas planas, particularmente, retângulos, quadrados e triângulos. Ao movimentarem os lados das figuras, deveriam emergir relações diferentes em cada atividade proposta. Muito embora as relações esperadas não tenham surgido imediatamente, pudemos perceber que o GeoGebra favoreceu muitos aspectos não verbalizados em relações matemáticas convencionais. Esses reiteram o que Teles e Bellemain (2011) afirmam serem os elementos do campo das grandezas geométricas, que expressam relações entre comprimentos de figuras geométricas planas, as quais desempenham papel importante na aprendizagem do conceito de área. Isso pode ser observado no desenvolvimento das percepções adquiridas pelos alunos ao utilizarem o software.

A Geometria deixou, para a grande maioria, de representar uma Matemática estática, com resultados previsíveis e passa a fazer parte do próprio fazer dos alunos, conforme suas idades, em que o dinamismo é o combustível que os conduz. Eles são dinâmicos, não mais se conformam com aulas centradas na figura do professor, detentor do saber, do quadro e do giz. Ao utilizar o GeoGebra na aplicação da sequência didática, a concentração e o envolvimento na busca da construção do conhecimento foram ganhos concretos na relação ensino e aprendizagem.

Muito embora possa parecer que, ao confrontar a análise a priori com a posteriori, não tenhamos alcançado o objetivo pelo fato dos alunos não perceberem e explicitarem a relação entre a área e o perímetro das duas figuras azul e rosa, outras conquistas foram obtidas, como a concentração para a realização das atividades propostas, a imaginação, a criatividade, a interpretação e o raciocínio lógico, juntamente com o interesse em realizar as atividades.

\section{Considerações finais}

Entendemos que o fragmento da dissertação constante desse artigo ilustra, apenas parcialmente, o trabalho investigativo realizado na pesquisa de mestrado e que o objetivo de utilizar o GeoGebra, como ferramenta, para investigar como alunos de 6a série/70 ano do EF realizam a construção do conhecimento de perímetros e áreas de figuras geométricas planas, por meio de uma sequência didática, foi cumprido. Tal consideração prende-se ao fato de que nossas análises a priori e a posteriori podem comprovar crescimento na compreensão dos conceitos 
geométricos envolvidos em figuras planas, como área, perímetro, nomenclatura de figuras e até mesmo propriedades.

Ao analisar as dificuldades encontradas pelos alunos na resolução das atividades envolvendo figuras geométricas, os erros mais frequentes cometidos por eles na compreensão de perímetros e áreas, bem como as formas de caracterizarem tais figuras, entendemos que as questões de pesquisa propostas foram satisfatórias, especialmente pelo emprego do GeoGebra na sua resolução.

Considerando as observações feitas durante a aplicação das sessões da sequência didática, foi possível analisar o desempenho dos alunos durante a realização das mesmas. Nessas observações, levamos em conta a maneira como os alunos desenvolveram as atividades, como ocorreu a interação com o GeoGebra, qual a concentração ao raciocinarem sobre as atividades propostas, de que forma a curiosidade foi despertada ao manusear as "peças" na tela do computador, a necessidade de tirar as dúvidas com a professora e com a professora de informática, a qual auxiliou durante o decorrer da pesquisa.

Podemos concluir que os resultados obtidos, ao final da sessão 3, objeto deste artigo, foram satisfatórios, porque contribuíram para a evolução na construção de conceitos geométricos que os alunos não possuíam, bem como propriedades das figuras geométricas planas, principalmente as relacionadas com perímetros e áreas. Entretanto, até a aplicação desta sessão não é possível dar conta de responder ao problema de pesquisa bem como se o objetivo foi alcançado, sendo necessário para tal fazer a análise das sessões subsequentes. O que é possível afirmar até esta fase é que o segundo objetivo específico já pode ser considerado alcançado: verificar o uso do GeoGebra como ferramenta que possibilita a interatividade entre os alunos, no sentido de promover o ensino e a aprendizagem de conceitos relacionados com a geometria plana, especialmente pelo apontado no parágrafo anterior. Para não deixar em branco, na dissertação é indicado de que forma o objetivo geral traçado para a pesquisa foi parcialmente alcançado. Os argumentos que conduzem a tal afirmação não poderiam ser aqui apresentados em função da necessidade de trazer as demais sessões uma vez que o desenvolvimento dos alunos foi gradativamente ocorrendo.

Em nossa vivência como professores, verificávamos, em anos anteriores, que não desejavam estudar essa área do conhecimento matemático, o que é comprovado na pesquisa por meio de um questionário final aplicado. Ao serem questionados sobre "O que você aprendeu de Geometria utilizando esse software?", os alunos das duas turmas responderam, quase que unanimemente, que aprenderam sobre figuras geométricas e medidas dessas. Segundo $\mathrm{K}^{1}$ : “Eu aprendi várias coisas como o que é uma figura, o que é um perímetro de figura e quais seus

\footnotetext{
${ }^{1}$ As falas dos alunos foram transcritas literalmente.
} 
tamanhos tanto de comprimento quanto de largura". O aluno $\mathrm{H}^{\prime}$ disse: "Aprendi a conhecê-las melhor e a usar o raciocínio para aprender". A escrita de $\mathrm{P}$ "Eu aprendi que a área pode aumentar e diminuir e que as figuras são as mesmas em forma diferente" e "Aprendi o que é área, perímetro, aprendi a montar figura e a mexer os pontos das figuras tornando-as exóticas", ilustra o despertar dos estudantes para novos enfoques sobre Geometria.

Depois de fazer as atividades propostas nas aulas, você poderia escrever sobre Perímetro e Área? Se sim, faça-a. Após esse questionamento, obtivemos respostas de dois estudantes: "Sim, perímetro é o contorno de uma figura, área é o calculo do tamanho das figuras, medidas em centímetros quadrados" e "O perímetro é o contorno da figura e a área é por dentro da figura". Isso comprova nossas conclusões de que houve aprendizagem geométrica com a aplicação das atividades tanto da sessão 3 , quanto das demais, que vieram posteriormente e que serão objeto de outro artigo.

Por fim, a comprovação da relevância do GeoGebra é expressa nas respostas que traduzem o sentimento da grande maioria dos alunos, à questão a seguir: Você gostaria de aprender outros conteúdos de Matemática no GeoGebra? Quais? Por quê?

"Sim, mais coisas de geometria para aprender coisas novas" e "Sim porque valeu muito a pena vir à informática, assim aprendemos a lidar mais com o nosso raciocínio e por isso eu queria vir mais vezes para aprender sobre outros conteúdos". Esta explanação pode ilustrar o quanto houve a evolução dos alunos com a aplicação da sessão 3, considerando a análise a priori, em que os alunos desconheciam o software GeoGebra e, também, por se tratar de um conteúdo ainda não desenvolvido com a turma.

Assim, comprovamos, com a aplicação da sessão, que o suporte oferecido pelo GeoGebra tornou as aulas mais dinâmicas, possibilitando aos alunos proporem conjecturas e buscarem suas comprovações. Isso corrobora o afirmado por Kenski (2007): "softwares diferenciados transformam a realidade da aula tradicional, dinamizam o espaço de ensino-aprendizagem, onde, anteriormente, predominava a lousa, o giz, o livro e a voz do professor" (p.46).

Embora no artigo não tenhamos apresentado outras sessões da pesquisa realizada, por limitação de espaço em um único artigo, o leitor interessado poderá buscar as informações na dissertação disponibilizada no site do curso. Elas complementam o trabalho desenvolvido pela primeira autora e respondem ao problema de pesquisa que foi proposto para a dissertação. Concluímos que o uso de aplicativos computacionais, nesse caso o GeoGebra, possibilita o desenvolvimento de noções e conceitos geométricos, criando ambientes exploratórios em Geometria. Isso vem ao encontro do que os Parâmetros Curriculares Nacionais - PCN, afirmam sobre fazermos uso de outros recursos como o das tecnologias no estudo de Geometria. Além disso, comprovamos que o GeoGebra tornou-se uma ferramenta poderosa para a realização das 
atividades elaboradas na sequência didática, o que permitiu contribuir para um efetivo trabalho para o nível considerado.

\section{Referências}

ALMOULOUD, S. A. Fundamentos da didática da matemática. Curitiba: Editora da UFPR, 2001. BRASIL. Secretaria de Educação Fundamental. Parâmetros curriculares nacionais: Matemática. Brasília: MEC /SEF, 1998. Acessado em 15-07-2010. Disponível em <portal.mec.gov.br/seb/arquivos/pdf/ttransversais.pdf>.

KENSKI, V. M. Educação e Tecnologias: 0 novo ritmo da informação. Coleção: Papirus Educação. Campinas - SP. Editora: Papirus, 2007.

MACHADO, S. D. A. Educação Matemática: uma introdução/ Sílvia Dias Alcântara Machado. et. al. - São Paulo: EDUC, 1999.

PAIS, L. C. Uma análise da influência francesa. 2 ed. Belo Horizonte: Autêntica, 2002.

PAIS, L.C. Educação escolar e as tecnologias da informática. 1 ed., 2. reimp. Belo Horizonte. Autêntica, 2008.

SANCHO, J. M., HERNÁNDEZ, F.. Tecnologias para transformar a educação. Porto Alegre: Artmed, 2006.

TELES, R. A. de M.; BELLEMAIN, P.M.B. Um Estudo Sobre a Fórmula de Área para Otimização. In: CIAEM - XIII Conferência Interamericana de Educação Matemática. Anais... Recife, 2011.

José Carlos Pinto Leivas: professor do Mestrado Profissionalizante em Ensino de Física e de Matemática do Centro Universitário Franciscano de Santa Maria - RS - UNIFRA. leivasjc@unifra.br

Juliana Aparecida Gobbi: professora da rede estadual de ensino do estado do Rio Grande do Sul. julianaagobbi@hotmail.com 